\title{
The benefits and pitfalls of a multicultural teaching faculty and a monocultural student population: An interpretive analysis of tertiary teachers' and students' perceptions in the United Arab Emirates
}

\author{
P. J. Moore-Jones \\ University of California, Irvine, United States of America \\ pj.moore54@yahoo.com
}

\begin{abstract}
Emirati students at public universities have a wide demographic of faculty members teaching them courses in their second language, English. These faculty members bring with them their own cultural assumptions, epistemologies and use of language which at times are in stark contrast to those of the students.

The aim of the research is to shed light on the effects that a multicultural faculty have on a monocultural student body and vice versa. This study looks at both faculty and students' perceptions of public tertiary education in the UAE. Namely, the research questions surround themes regarding the benefits and pitfalls of multiculturalism in a university environment.

Contentions are made based on qualitative data received regarding the levels of intercultural competence of both faculty and students. Noted are the importance of intercultural competence, how and why it is significant to have not only as a globalized member of a multicultural teaching faculty but how and why it is a central skill the fresh graduates must develop during their undergraduate careers.
\end{abstract}

\section{Keywords}

multiculturalism in education, intercultural competence, the UAE

\section{Rationale for the study}

With the advent of study abroad programs, with the advent of affirmative action, with the influx of English as a Second Language programs leading to higher international student populations and with the advent of a globalized world, much has been written, researched and studied about multicultural classrooms, how educators can deal with the wide spectrum of cultures within one classroom and the increasing necessity of multicultural competency for faculty in all levels of education (Brown-Glaude, 2009). However, quite a contrary dynamic occurs in the United Arab Emirates, specifically in public institutions of higher learning. Here, it is the faculty which is multicultural and the student population is one which could be characterized as of a single, national and religious culture.

Emirati students studying at the University of the Emirates (a pseudonym), one of three major public institutions of higher learning, have a wide demographic of faculty members teaching them an equally wide variety of courses. All of these courses are mandated to be taught in English. These faculty members bring with them their own cultural assumptions, methods, expectations, educational practices and use of language. While, previous studies explored what faculty members are responsible to know and understand with a multicultural student population, I look at the United Arab Emirates and wish to know more about the effects of a multicultural faculty teaching a monocultural student population. Referring specifically to students who conduct their studies in a second language, Badger \& MacDonald (2007) argue that there is a difference of culture between learners and educators and acknowledgement of that difference is crucial in understanding students' needs and academic progress. Often times what occurs in the classroom is the students bring in their own cultural assumptions, ideas, tendencies and 
expectations while the teacher comes in with what may be completely differing sets of each. This idea is noted by Mughan who states "In order for language learners to apply the language skills fruitfully and effectively, a knowledge of the cultural environment is essential" (Mughan, 1998, p. 43). This "cultural environment" that Mughan speaks of is comprised of the two sets of these cultural dynamics. What will be covered in in my recommendations is that a negotiated 3rd cultural space is needed to be created by both parties in successful classrooms where the teachers and students may differ in educational assumptions.

Glowacki-Dudka \& Treff (2011) note in a study of a Saudi Arabian college that a multicultural faculty "need to be conscious of the cultural assumptions faculty and administrators bring with them" (p. 217). Generally speaking, it can be said that most faculty members have been educated in their own country and therefore bring a certain style of learning, a certain style of instruction and a methodology of teaching with them to the United Arab Emirates. Although many faculty members have taught elsewhere in the world as well, it is our native mode of education that tends to stand out when we, as educators, approach teaching a course in a second culture. Diallo (2014) echoes the sentiments made by Glowacki-Dudka \& Treff and speaks more specifically and recently about the states of educational dynamics in the UAE. She writes,

Large scale importation of Western-trained language teachers to teach in a non-Western educational context poses challenges because teachers and students tend to operate from within their own distinct, social, cultural and educational paradigm. Teachers draw on Western educational models and pedagogies to teach students who have different, if not opposing, educational values and epistemologies. (Diallo, 2014, p. 1)

\section{Context}

This study focuses on students and faculty of Dubai Women's Campus and Dubai Men's Campus of the University of the Emirates, hereafter referred to as the U of E. The U of E was founded in 1989 with respective Men's and Women's campuses.

The students of public institutions in the UAE can be described as belonging to what Holliday calls the same "large culture" meaning that they are all of the same nationality (Holliday, 2002). From this, we know that they have come from secondary education systems which follow similar curriculums, be they public or private. They are also all Muslim and follow Emirati interpretations of Islam. This is mentioned due to the fact that some faculty members encounter facets of Emirati religious practice (i.e. frequent prayer) that they may not have been used to in their home country. All of the student participants are Emirati citizens.

Faculty come to the $\mathrm{U}$ of $\mathrm{E}$ from all corners of the globe. They are recruited online and through academic conferences such as TESOL Arabia, and are given a package to relocate to the UAE for a 3-year contract, after which they are reviewed by the university leading to a decision as to whether a renewed 3 -year contract would be offered. Some nationalities are represented more than others due to a number of factors, most prominent being general proximity to the UAE. Those represented as faculty include but are not limited to British, Irish, American, Canadian, Jordanian, Egyptian, Indian, Filipino, Sudanese, Pakistani, Tunisian, Iraqi, Chinese, Brazilian, Dutch and several others.

\section{Conceptual framework}

\section{Muller's 3 circles of worldview}

This work draws heavily on the work of Roland Muller and the interworkings of intercultural competence (Knowledgeworkx Inc., 2013). Knowledgeworkx uses arguments and contentions made by Muller to establish a working definition of "culture" in a way that does not categorize or over-generalize nations or cultures as one way or the other but rather creates a picture of worldviews and ontologies that can, however, be described as being generally accepted and common in certain regions of the world and atypical in others. 
Muller argues that there are but 3 circles of worldview and every human on Earth from every culture possesses elements and differing degrees of all 3 (Muller, 2001). What he goes on to argue and what Knowledgeworkx furthers to profess is that certain regions of the world include cultures which we can analytically assume are more dominant in one circle than others. The circles consist of opposing binaries of Guilt/Innocence, Power/Fear and Honor/Shame and appear thus,

Figure 1 - Muller's 3 circles of worldview

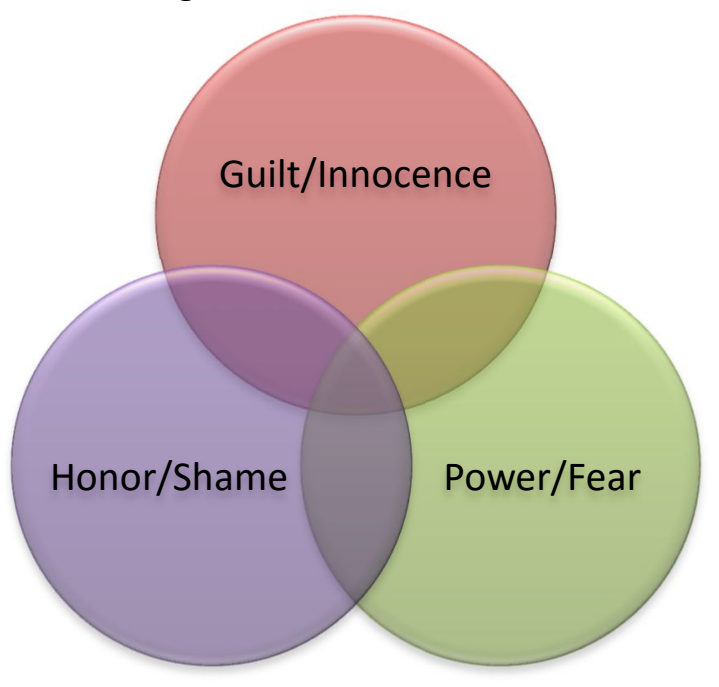

Muller describes these worldviews as main motivators that drive one's decision-making processes and in turn, their behavior (2001). How each culture values or undervalues each of the 3 circles is dependent on a variety of factors that may exist more prominently within the culture. These include political climate, religion, law and the direct or indirect application of it, relationship, group membership and many others.

Muller offers a useful framework for analysis of the data. He offers in this study his 3 Circles of Worldview which holds the notion that every human being, having been raised and acculturated in any region of the world, or even exposed to, studied, adapted to or even adopted ways of other cultures, possess elements of what he calls the 3 circles of worldviews (Muller, 2001). Regardless of what culture one was raised in or what one has learned, all aspects of all three circles exist and are prevalent in all people of the world. Each person, however, is likely to have an ontology and live their lives by the cultural tenets of a dominant circle and Muller therefore, attempts to provide generalizations as to which cultures tend to value certain circles over others. These circles, vary in dominance from person to person and may, in fact, evolve and change over time due to a variety of factors including but not limited to globalization, exposure to other worldviews, ebbing and flowing one's own personal faith, age, education and number of unpredictable variables.

Muller (2001) speaks of the globalized world and how while some cultures may have been driven purely or predominantly by one worldview or another, they are evolving into ones which yield a more equally distributed and mixed variety. When discussing the development and existence of the 3 worldviews, Muller writes "Some cultures have more than another, but all three are present in all cultures today" (Muller, 2001, p. 19). Therefore, attempting to fit or classify each culture into one or another becomes problematic while one worldview is mostly dominant, that is not to discount the existence, influence and effect of the other two. Further, one cannot accurately predict when the precepts and effects of the two lesser dominant worldviews may be the ones which dictate certain behavior. 


\section{Guilt \& innocence}

A Guilt/Innocence worldview is one which sees the world in terms of rules, regulations, correct, incorrect, right and wrong. It is one in which a person with this worldview bases his or her own actions and behavior on what is "the right thing", one which results in the doer to ascend onto a higher level of perceived correctness. People with this worldview often prefer clear guidelines, boundaries and definition in their daily lives. Consequently, cultures in which people with this dominant worldview live often do have complex legal systems and a high number of correctional institutions. Notions exist that what is wrong is wrong, even if no one else knows and if others were to learn of wrongdoing, there are policies, procedures and systems to ensure punishment and consequence. Individuals are raised and groomed to make right choices and resist temptation of wrong ones. With these notions is the idea that one will be fine as long as one "walks the line".

Cultures with this predominance tend to be highly individualistic and are found, according to Muller, primarily in the Western world. As he claims, "[M]uch of the English-speaking world and parts of Europe have worldviews that focus on the aspect of man's guilt, and/or his freedom from guilt" (Muller, 2001, p. 18). Muller embraces the metaphor of a pool of swimmers enjoying the sun and a lifeguard on duty. When the lifeguard blows his whistle, swimmers from a Guilt/Innocence dominated culture are likely to stop what they are doing, look around and seek to find the source of the issue. The notion that it might have been them that has caused the alert is what stops them to check if what they have been doing might have been wrong. The initial reaction from someone with this dominant worldview is that of guilt.

\section{Honor \& shame}

This worldview differs from Guilt/Innocence in that it is not the right and wrong of things that inform their worldview and therefore their behavior, but rather concern for the group to which they belong. Reputation, honor, shame, image and blasphemy are some elements that influence behavior. Protection of the group is synonymous with what one with a Guilt/Innocence worldview would consider protection of one's self. The name, reputation, image and sanctity of the group speaks louder to man than that of the individual. Honor is defined as what gives one status in the eyes of others.

Muller sees people who have a more Honor/Shame worldview tend to be more collectivist and often are of cultures in the Middle East and East Asia (Muller, 2001). "The other side of shame is honor, and every Arab desires and strives to be and become more honorable. The relationship between shame and honor has long been recognized by sociologists of Arab and Muslim cultures and also attributed to the generalized Mediterranean social complex" (Muller, 2001, p. 88).

Along with the same metaphor, when the lifeguard blows his whistle, people with an Honor/Shame worldview might have a different reaction. Instead of stopping their actions like a Guilt/Innocence culture would, people from an Honor/Shame culture are likely to continue what they are doing, with full knowledge that what they are doing is not the reason for the whistle. Although they might end up looking around out of sheer curiosity, they will not have the immediate assumption of guilt of their own action like others might.

Muller, being of a Western, Guilt/Innocence worldview set out to write his philosophy based on his own and others frustrations in teaching in cultures with a Honor/Shame worldview. He states that he has had much difficulty relaying messages and educating youths in the Middle Eastern world (Muller, 2001). He suggests those coming from different worldviews need to alter their approach only after understanding the differences that exist. Regarding Shame-based cultures, he maintains that "[I]n our culture (Western, Guilt/Innocence) telling the truth is right and telling lies is wrong. In the Middle East, people don't think of lies as being right or wrong. The question is, 'is what is being said honorable'? If a lie protects the honor of a tribe or nation, then it is fine. If a lie is told for purely selfish reasons, then it is shameful" (Muller, 2001).

This broad stroke reasoning may seem reductive. One must remember that Muller's ethnocentrism is something that one can expect to be projected. In other words, Muller's worldview is one made up of a 
predominately Guilt/Innocence perspective, therefore the above quote is stated from a perspective of difference. However, I believe it speaks to multiple dynamics which exist in the world of education. Such instances can occur with students from differing worldviews as well. I can certainly think of many instances when students have told me something that I have questioned to be true in cultures which Muller describes as Honor/Shame as well as in those which he describes as Guilt/Innocence. What Muller also often does is to attribute these differences in worldview to differences in faith and religion; in this case he speaks directly to Middle Eastern, Muslim students. To me, this seems to be a road too easily travelled. Certainly one can look at any Holy book and find instances of all 3 circles being taught. To say that one is more pronounced in one book than others is a matter of interpretation.

In today's world, we are seeing a global clash primarily between the younger generations and the worrisome elder generation with stronger Honor/Shame worldviews. Through globalization, study exchanges, the growth of the English language, travel and other international exposures, a strict Honor/Shame heritage and set of cultural values are, at times, being marginalized. Some women jettison their sheilas, prefer attention-seeking beauty products and fashion as opposed to the modest and nondescript abayas. Young people are dating and rejecting the interfamily, arranged marriages that have been the norm for generations (Diallo, 2014). These examples often cause conflict among family members as a younger generation, at times, are seen as disregarding the honor of the collective group by projecting individualistic, Guilt/Innocence values.

\section{Power \& fear}

The third of Muller's 3 circles in the worldview is dominated by Power/Fear. This worldview is often associated with power structures which include elaborate or absolute systems of hierarchy within the government, organization or family. This is a worldview which includes things like consequence and punishment as well as reward and positive acknowledgment of merit. These structures can be found anywhere from a small scale like the family home and behaviors of parenting to large government organizations (Muller, 2001). They use people's fear by instilling it and the exercise of power to yield the desired results. Leaders tend to hone managerial skills to enhance their power over the masses. Regarding these systems where absolute monarchies and dictatorships are often the political structures, abuse mechanisms can often be seen to maintain and expand power bases.

A Power/Fear worldview is based on animism, from the Latin root "anima" for "soul" (Muller, 2001). The animistic worldview interprets everything from a spiritual philosophy rather than a materialistic one (Muller, 2001). This worldview is also attributed to cultures in which superstitions, rituals and other group-based beliefs systems are more prevalent than others. At times, the fear of the supernatural and heeding of its warnings play a large part of dictating behavior within the culture. Positive outcomes of this worldview include a heightened sense of trust amongst those being ruled as well as a sense of control over destiny and circumstances of one's life. However, this ruling system often includes threats, harsh punishment and oppression that are not uncommon in such dictatorships around the world.

Reverting back to the lifeguard metaphor, when the lifeguard were to blow his whistle, those coming from a Power/Fear worldview would likely begin to worry and be afraid in a more immediate sense of those from a Guilt/Innocence perspective. The lifeguard being a person of power, might impose a punishment or consequence to those in the wrong, whoever those may be.

\section{Chapman et al.'s "Unsettled Journey"}

Chapman et. al. took a more broad approach to exploring UAE expatriate teachers' perceptions than this study. This team of researchers interviewed teachers from all 3 federal institutions of higher learning throughout the 7 Emirates to learn their views on a wide variety of issues in their professional careers (Chapman, Austin, Farah, Wilson, \& Ridge, 2014). Included in these themes were their participants' views on collegiality or faculty members' relationships and rapport with fellow multicultural teaching faculty as well as autonomy which they define as "discretion they have in making professional decisions about how they will organize and undertake their work" (Chapman, Austin, 
Farah, Wilson, \& Ridge, 2014, p. 135). Their expectation before the study was due to the fact that multiple nationalities cultures of participants would yield varying result in terms of job satisfaction, this was realized in part (Chapman, Austin, Farah, Wilson, \& Ridge, 2014).

Their aims and much of their rationale for their inquiry revolved around the broad implications it has for all institutions of higher learning, which employ a multicultural teaching faculty (Chapman, Austin, Farah, Wilson, \& Ridge, 2014). As they state that those who did choose to participate in their study view the expatriate faculty in the United Arab Emirates "transient and easily replaceable" (Chapman, Austin, Farah, Wilson, \& Ridge, 2014, p. 148).

Their participants generally noted that the working relationship that was had amongst the multicultural teaching faculty was harmonious and it was only when the "top-down model" of administration affected their work was there ever any discontent (Chapman, Austin, Farah, Wilson, \& Ridge, 2014). Some of their participants were faculty from the University of the Emirates and while they stated that they generally feel they had autonomy in their teaching practice, they were concerned over the lack of participation in the governance and design of curriculum which they feel had been handed down to them (Chapman, Austin, Farah, Wilson, \& Ridge, 2014). Additionally, faculty participants felt afraid of offering any criticism of the curriculum which many believed "could cost them their job" and such criticism was "not welcomed and poorly tolerated" (Chapman, Austin, Farah, Wilson, \& Ridge, 2014, p. 145). Moreover, their participants gave the overall view of their higher education in the UAE as a "superficial system" which is a theme that recurs in the data of this study as well (Chapman, Austin, Farah, Wilson, \& Ridge, 2014).

These authors posit that while collegiality amongst the faculty is benevolent, there are often issues between themselves and their Emirati students and the Emirati administration which they believe is a result of differing values (Chapman, Austin, Farah, Wilson, \& Ridge, 2014). "Goals collide" as they state in terms of faculty motivation to conduct effective lessons for their students and the influence they tend to not have in terms of design, suggestion or criticism of current curricula (Chapman, Austin, Farah, Wilson, \& Ridge, 2014, p. 149). Chapman et. al (2014) conclude by suggesting that the institutions which employ their participants have missed an opportunity in the beginning stages to offer support and "mechanisms to meaningfully engage these instructors to professional life" in the region and "allow them to feel valued as professional colleagues" (Chapman, Austin, Farah, Wilson, \& Ridge, 2014, p. 150).

\section{Methodology}

A qualitative approach is employed with the collection of data of a single yet extensive line of inquiry. The data collected for this study are qualitative, conducted through semi-structured interviews from an interpretivist approach. These interviews and the qualitative data were expected to produce indepth responses such as anecdotes, examples, exceptions and a social reality of the experiences of the participants. This is in an effort to construct "culturally derived and historically situated interpretations of the social life world" which can most effectively be collected through qualitative data such as interviews (Crotty, 1998, p. 67). In addition, interview items are constructed in a way to give me as the researcher as well as the reader a clearer sense of which of Muller's worldviews is dominant in each participant.

The constructivist relationship between the teaching faculty members and the students is one in which we make sense of the phenomena. We live the dynamics of it and thus the impossibility of the participants or I as the researcher, to remove ourselves from it, binds us. As a result, the idealistic notion of complete objectivity in this research and the separation of myself from the phenomena is a non-starter. I wished to learn more. I wished through research and collection of qualitative data, to have a self-reflective process that enabled me to know myself within the experience being investigated. Ultimately both personal and social knowledge are needed to arrive at valid understandings of reality, I must first be attuned to my own being, thinking and choosing before I relate to others' thoughts, understandings and choices. I must arrive at my own sense of nature and meaning of something, make 
my own decision regarding its truth and value before I consider the point of view of others. (Moustakas, 1994, p. 121)

In addition to this, a separate aim of this study is to examine students' perceptions of their lived, educational experience with a multicultural faculty. Having a much more limited experience with being taught by a multicultural faculty, I offer my own professional experience to relate to students' input. This approach to the research includes my own experiences with the students, my challenges, successes and failures as a faculty member. Drawn side by side with that of my teaching faculty participants' perceptions, the student participants' responses served to elucidate the phenomena via their own lived, educational experiences which remain broader, having lived the phenomena several more times in several more courses. As Creswell (1998) states, I sought through the collection of qualitative data to "search for essentials, invariant structure (or essence) of the central underlying meaning of the experience" (p. 52).

The qualitative design of this research is divided into two parts, the interviews which were conducted with the faculty members and the focus groups conducted with the students. The teaching faculty members were interviewed in a semi-structured format for a variety of reasons. First, the interview format was chosen in an effort for the participants to discuss interpretations of their teaching experiences and express how they regard situations from their own perspective. Members of the teaching faculty are also the multicultural participants which this study seeks to explore the perceptions, effects and experiences of. The participants come from culturally diverse backgrounds. An example of this would be that some of the participants are from cultures which Hofstede characterizes as more Individualist while others come cultures which are characterized as Collectivist (Hofstede, 1980). Due to the variety of length of experience, culture of origin, age and previous locations of teaching experience, the decision was made to collect this qualitative data individually in one-on-one interviews.

Students were interviewed (See Appendix A) in focus groups in attempt to allow group discussions and interaction to develop as well as a range of responses (Watts \& Ebbut, 1987). The student participants in each focus group had been together for over 2 years, have had the same teachers and courses. As institutional practice dictates, they have been on the same academic journey together. This type of data collection also allows participants of the group to cross-check responses, contribute additional points, clarify or argue responses which leads to a more complete and reliable record of data (Arksey \& Knight, 1999). The focus group format also allowed for a comfortable and relaxed atmosphere among the student participants which lessened the feeling of interrogation among them. I encouraged the student participants to speak freely, build upon or counterpoint the responses of their fellow classmates. Furthermore, the focus group interviews were conducted solely in English to native Arabic speaking students which allowed for student participants to help each other in translation of words or points they wished to express which would not have been possible with individual interviews. In addition to this, a fellow Arabic-speaking colleague (non-participant) was present in all of the focus groups to offer translation if needed. It should be noted however that this external translator was not needed throughout any of the focus groups. The precaution was made, however, to negate any possible effects on the credibility and ensure the reliability of the data.

\section{Data analysis}

Two methods of analysis were used to code responses and reorganize recurring themes of them. Initially, all data were transcribed using Evernote and printed to allow me to highlight frequency of terms, variety of responses and to give me hard copies with which I prefer to work with. In addition to this, I copied and pasted the transcriptions into NVIVO to give alternative views of data. With NVIVO, I reorganized the data to allow me to see not only the straight transcriptions, but also a view of seeing responses to specific question items side by side. For example, I wanted to see how each faculty participant responded to the item regarding classroom management. I simply ran an inquiry for each 
response regarding question item \#20 and was able to analyze the variety of responses. This was done for all of the question items however, follow-up questions varied with each participant.

\section{Research questions \& findings}

Table 1 - Classification of themes (both faculty \& students)

\begin{tabular}{|c|c|c|}
\hline Research Question(s) & Themes & Sub-themes \\
\hline \multirow[t]{2}{*}{$\begin{array}{l}\text { (Faculty)How do } \\
\text { faculty members } \\
\text { perceive their } \\
\text { multicultural working } \\
\text { environment? }\end{array}$} & $\begin{array}{l}\text { Benefits of a } \\
\text { multicultural } \\
\text { teaching } \\
\text { faculty }\end{array}$ & $\begin{array}{l}\text { - Exposure to varieties of English } \\
\text { - Exposure of differing perspectives and } \\
\text { philosophies } \\
\text { - Competence for future work } \\
\text { Better working relationship and understanding } \\
\text { of "the other" } \\
\text { Preparation for a globalized society } \\
\text { Wider understanding of Emirati citizens (for } \\
\text { faculty) } \\
\text { Wider understanding of other cultures (for } \\
\text { students) }\end{array}$ \\
\hline & $\begin{array}{l}\text { Pitfalls of a } \\
\text { multicultural } \\
\text { teaching } \\
\text { faculty }\end{array}$ & $\begin{array}{l}\text { Difficulty with varieties of English } \\
\text { - Misunderstandings of culture \& religion } \\
\text { - Differing teachers' expectations } \\
\text { - Lower standards } \\
\text { - Gender issues } \\
\text { - Standardization issues among the faculty }\end{array}$ \\
\hline
\end{tabular}

Faculty members and students were questioned regarding their perceptions of the multicultural teaching faculty and the perceived benefits. Faculty members were asked to comment on both the dynamic that exists amongst themselves and also in relation to the students. Before the explicit question items were addressed, a brief discussion was had about what the term "multicultural" means. Most respondents, both faculty and student cited difference of nationality and "surface" culture or the "tip of the iceberg" that Peterson and others have cited, these being observable elements of culture such as dress, music, food, etc. (Peterson, 2004). Others cited the differences of culture in ways akin to how Holliday (2005) describes it as a "social force which is evident wherever it emerges to be significant" (23). In other words, some participants described elements of culture which are under the surface, are less observable such as religious or ontological positions. Perhaps there is no more significant place where social forces can be evident than an educational setting where outcomes and assessment of academic competence are most crucial. Participants were asked their views on the multiculturalism of the $\mathrm{U}$ of $\mathrm{E}$.

Carry, Canada: Yes, it is [multicultural]. Well, where we work, the teachers are from a variety of different countries not just Western countries we have teachers on our staff from China, from India, from Syria, from Palestine, from the Netherlands and so forth. So, I believe it is a multicultural place. 
Abdulrazak, Algeria: At the faculty level, we have so many individuals from different backgrounds, from different ethnic backgrounds, different countries, different cultures. But we teach one culture of students, the locals.

All participant faculty members agreed and acknowledged the fact that the $U$ of $E$ could be considered multicultural which is representative of the demographic of the UAE as a whole. Many faculty participants commented the degree of multiculturalism as a difference from institutions where they had previously taught and how it has helped and been advantageous to their teaching practice.

These statements were verified by students who often differentiated their experience of cultures of teachers from their secondary educational institution (both public and private) and the $U$ of $E$. This is exemplified by the response from Abdullah.

Abdullah, UAE: Yeah, of course. Here my IT teacher is from India, my Ethics teacher is from Britain, I had an IELTS teacher from China, Finance is from Syria. This is a very multicultural place. My teachers have always come from abroad, since primary school but here at $U$ of $E$, there are so many cultures teaching me. Every class is different.

\subsection{Perceived benefits of a multicultural faculty}

After this, further inquiry was made to find out what, if any were the perceived benefits of having such a multicultural teaching faculty. Here, I wish to present the data from the students first as it pertains exclusively to their classroom experiences. The faculty responses deal both their classroom experiences and their perceptions of the workplace.

Abdullah, UAE: Well, one benefit I had was that I could learn more about other cultures from my teachers, especially from Britain, Scotland, Ireland and these cultures. I also increased my language skills more than before. At the same time, I had to get used to their language, like the way they speak. It was difficult at first. One class I had a British teacher, which was hard anyway then I turned around and had an Indian for another class with a completely different way of speaking and communicating. I mean, one teacher could say one word and another teacher would use the same word with a different meaning. I had to learn what the word "hall" meant with different teachers. I thought it meant the same as corridor but sometimes it means classroom. So it was difficult to get used to them. I'm always having to translate what I learn in class to understand it.

The above response is consistent with other responses from students in saying that the multicultural teaching faculty they had been educated by presented benefits and also challenges to them in terms of language. Responses regarding these challenges reflected what was found in the literature as to the compounding of language and subject matter as elements of education that made their learning especially arduous to grasp and completely understand (DeCapua \& Wintergerst, 2004). What Abdullah mentions above is an example of simple difference of varieties of English. However, when deeper conceptual instances of English interfering with their understanding of subject matter exist, DeCapua \& Wintergerst's point become clear.

Students also suggested the multiculturalism present in their education has also affected their sense of identity, especially in regards to language. As Yousef states $(\underline{U A E)}$ : I feel I'm more of a citizen of world now, not only a citizen of the UAE. I couldn't be that without the ability to speak English.

While most responded that they felt the bicultural and bilingual skills that they will finish their education with will help them in their future lives, these are sentiments which echo what Moya (2009) has said that these "evolving products" of identity will continue to affect not only the students' own sense of identity but also how the students are identified by outside communities (45). 
A general sense of gratitude and appreciation came from the student participants when posed this question. However, most students, as Abdullah's response shows were quick to touch on the other side of this, being the pitfalls of such multiculturalism, and give an explicit sense that studying their subject matter in English as a complement to their education was something that they only realized on the other side of mental labor. This indicates that some students feel that doing their higher education studies in a second language is something that linguistically they were not prepared for. Further interpretation in this chapter suggests additional cultural elements are aspects of the learning environment which pose challenges to students as well.

Interestingly, the participant Jamila had a different take on the experience of having a multicultural teaching faculty which will be explored further in later themes.

Lamila, UAE: From my experience, I haven't seen or had any benefits from having teachers from other cultures. For me, it just makes my studies and my life harder. Just give us all British or all American, or all Arabic that way we know the way the class will be, the way the language will be.

This compounding of content and language was deemed unnecessary by Jamila who seemed more concerned with the content and concepts of her major (Electrical Engineering) than with the linguistic obstacles which she noted were constantly in her way. Some students responded that this was simply too much to take in in terms of academic concepts through a second language which they had to then decipher. As Saif states,

Saif, UAE: Sometimes, I find it hard to understand everyone. Like, you think you know but actually, you don't really get what they just said. It's hard for me to learn, always guessing.

Faculty members had differing perceptions of the benefits of a multicultural faculty both in terms of student outcomes and of what their lived experience is and has been in terms of working with multicultural colleagues. Here it is evidenced by the data that the differences of faculty members' perceptions are not things that are always present in the eyes of the students. Students often noted the differences in how teachers conduct their classes while faculty members often cited the differences in the day-to-day-activities in the workplace as what primarily comes to mind when questioned about the phenomena.

Samira, Lebanon: We can learn from each other different ways of doing things, conducting our classes and managing our duties. I have the pleasure of observing some of my colleagues from America last semester and found their styles of teaching completely different from mine. I took a few pages from their way of doing things. It helps us all to gain a better perspective.

The response from Samira was especially telling that the teachers can be open and willing to learn new approaches than simply the approach of 'teach as you were taught' which is something that can be expected to grow and develop amongst the teachers as time and service go on in this teaching context. Considering contentions made by Glowacki-Dudka \& Treff (2011) as well as Diallo (2014) that teachers in such an international context conduct their classes in ways and with methods native to their own ways of studying, Samira might agree that to say teachers do this exclusively, might be selling us all short. These contentions leave no room for teaching to alter, add to or amend their approaches which is what many of us do and is evidenced by Samira's response (Moore-Jones, 2014).

Participant Carry has a different point of view.

Carry, Canada: Uh, well, I guess it is [beneficial] but I think as the faculty are multicultural, that's who the U of E could get to do the job; it's who they could get to live and work here. To be honest, I'm not sure if they had the students' interests in mind first. 
The complexity and cultural diversity of teaching staff may, according to Carry, be a byproduct of other necessities both on parts of the Ministry of Higher Education and the teachers themselves and not by design to benefit the students. In other words, the multiculturalism that the $U$ of $E$ and other institutions employ, according to Carry, could be the consequence of recruiting in a wide variety of regions of the world, amongst a wide variety of cultures to ensure retaining the required number of staff. While this may be perceived as a benefit and an initiative to expose Emirati students to a variety of cultures in their education, Carry seems to think faculty retention may the actual motivation of such recruiting.

\title{
5.2 Perceived pitfalls of having a multicultural teaching faculty
}

I begin this section with the responses from the teaching faculty. Explored are perceived challenges present in the teachers' lived experience and were often followed up for expansion, clarification and examples.

\begin{abstract}
Andrew, Canada: Yeah, I think it's probably more likely that you'll have more misunderstandings between the students and yourself, between colleagues from a different culture and yourself. You know, it's a tough job, it's stressful and people have different ideas about how to do their jobs and how to handle things. I mean, normally in teaching you're pretty independent but when there's a push to standardize things, it can get messy. You might be working with an older colleague from a hierarchical society which expects you to blindly follow his or her way and since you're younger, it's ok for them to tell you what to do and that doesn't always go over very well.
\end{abstract}

Here Andrew speaks directly to how the differences of worldview can and do cause conflict in the lives of the teaching faculty. Someone coming from a culture which is predominately of a Power / Fear culture which consists of what Andrew call "a hierarchical society" might have differing expectations from his students and even fellow teachers (Muller, 2001). What Andrew (coming from Canada, a region which Muller describes as predominately Guilt / Innocence) might expect in a professional situation is clear guidelines between right and wrong in certain contexts, these would be outweighed by the economies of power, that someone from a Power / Fear culture might value (Muller, 2001; Foucault, 1980). In the example that Andrew gives, the variable of age affects the relationship between himself and his rhetorical example (Foucault, 1980). This mismatch of cultural values tends, according to Andrew, to cause problems in the difference of professional expectations and willingness to work together.

Hanna's response seems less than optimistic about the prospect of having such diverse worldviews in a teaching faculty.

Hanna, England: If we were a homogeneous group of educators who had all been trained, you know, in the same country, we would all be able to say that we've all got a good idea of what assessment is and what it should consist of, what rubrics and scales are used and be fairly confident. It's ludicrous to think we all [at the U of E] have the same ideas about assessments.

From response, it seems Hanna might well agree with the previous comment by Jamila in stating that should all things be equal in epistemology or even worldview, things might run smoother where all parties involved, both students and teachers were on the same page in terms of academic expectations and accountability.

Sarah also believes there is variance in teaching styles and language. On top of what Yasmin mentions about how multicultural team dynamics and decision translate into what happens in the classroom. Sarah also points the differing expectations and outcomes of the courses that multicultural team members have. 
Sarah, Wales: I think the differences of [English] dialects have effects [on students] and also students have a variety of teaching styles that students have to contend with. But I also think that because of the way we've been taught, there's also an influence on our instinctive teaching style. Obviously, culture has a lot to do with teaching styles as well. And it's difficult for students, having been taught in manydifferent ways bydifferent teachers at the same time and also having different expectations from the teachers. Not only that, but the skills and the types of knowledge that we are hoping students will develop, I think are also different.

Sarah cites more challenges in the compounded cultures of academia. While Yasmin points to differences in how teachers conducted their classes, Sarah takes a step back from this in saying that our differing varieties of English as well as differing expectations of students often inform our practice thus leading to even further divergence in what the students may experience in the classroom.

Although most participants tend to agree with Glowacki-Dudka \& Treff (2011) that certain cultural assumptions and practices from our own native education experience find their way in our own practice here in the UAE, remaining strict and stubborn to such epistemologies and practices could hinder one's cultural exploration and adaptation. More importantly, imposing one's native educational culture's practice without consideration of the target culture impedes one's ability to create a negotiated $3^{\text {rd }}$ cultural space and some would argue borders on cultural imperialism in education (Said, 1993).

Noted responses regarding the benefits of having a multicultural teaching faculty is that the exposure the students receive to differing epistemologies, teaching practices and varieties of English is expected to produce more well-rounded graduates in terms of cultural and linguistic duality. However, as mentioned by Carry earlier, the students' best interests may not have been in mind and one could argue that failure to amend and alter one's teaching approach and to commit to and rely solely on one's own idea of how teaching and learning work is to impose an educational ideology on another culture. It also rejects what Moore-Jones (2014) states in that changing and altering one's own teaching approach based on the culture in which one teaching is beneficial to both the teacher and the student as a vehicle to promote intercultural competence. To him, one cannot rely solely on models and styles of teaching that one was educated in and has previously taught but rather adjustment of approach is necessary to conduct effective and successful teaching (Moore-Jones, 2014).

Throughout the various responses regarding both the benefits and challenges of the having a multicultural teaching faculty, I found that Murphy's summation covered many of the aspects of the phenomena. The following excerpt demonstrates the participant's understanding of the linguistic and educational dynamics that are at play in such a multicultural environment. In such an ethnically, linguistically and ontologically diverse setting as Dubai, the struggles, challenges and obstacles can often be the best teaching tools. This participant seems to understand how this fits into Emirati students' higher education.

Murphy, England: Well, I think the pitfalls and the advantages are the same. Language and culture are indistinguishable. So are idiolects and our culture. They are tied together so the way we use language, formulate language and emote language is connected to our culture in a way which is inseparable. So that is the problem in trying to teach a homogenous language but it's also an advantage in terms of being able to give insights in the culture of where the people come from.

Students had much more concrete examples of times when their education had been challenging due to the multiplicity of cultures in their classroom. When asked about the pitfalls of such a multicultural setting, responses from students covered a wide range of topics. 
Ahmed, UAE: Some teachers expect us to do something we can't do because of our culture. For example, one project we had was to interview a manager of a company and find out about the industry and the IT needs and data servers of the company. The particular company we were interested in had a woman manager and some guys in my group didn't want to talk to her. They said this is not allowed. So we couldn't do the project the way that the teachers wanted.

Examples such as this clearly exemplify the expectations of the teachers regarding assessments. Certain steps or actions within the assessments or projects that the teacher may feel will offer an experiential model for learning may offer tension between the accepted norms of Emirati students. An instance such as the one mentioned by Ahmed offers a look into how deep the worldview of Honor / Shame can be. It is not only the significance of such a worldview that distinguishes these students from some of the faculty members but the entire notions of what is honorable and what is shameful. I doubt any faculty member would ask students to embark on a project or assessment which they deemed to be inappropriate or shameful. This is often the root of the issue in that there exists a great divide between definitions of these things. In this case, the teacher assigned this assessment with the mindset that talking to a female would not be a problem for the students. To Ahmed and others, speaking to a female, even in a professional manner might be considered a shameful mark on themselves or their family. Not all students feel this way but it is evident that Ahmed does and thus we can assume others do as well. An example of intercultural competence on the part of the teachers would be giving assessments and projects which do not impose their own cultural norms on students whose norms may differ.

Just as teachers profit culturally from having time to learn the intercultural competence required to function and teach effectively with Emirati students, the students also sharpen their cultural skills with time in what can be an academic, cultural and linguistic obstacle course. Yousef states,

Yousef, UAE: Well, maybe I had some difficulty in the beginning because I had to adjust to different kinds of teaching and all the kinds of English. But then after 2 or 3 years, I've learned how to do this well.

Mohammed suggests differences exist in terms of classroom management as well. A certain practice in particular which he has experienced before to be acceptable is no longer.

Mohammed, UAE: Just the different rules. I mean my British teachers don't like when someone just jumps in an interrupts, which is the way many of our other classes are taught and that's what we are used to. Don't do that with a British teacher. No, no.

Although Mohammed's response might seem humorous, this speaks to tempering and balance of cultural dimensions that he has learned. This has led him to amend and alter his classroom and academic practices from one class to another.

Participant Bashayer disregarded the phenomena as being a challenge or difficulty citing that,

Bashaver, UAE: I can't say I've had a lot of difficulty because the UAE is a multicultural place so I'm used to it. I had a different education though. I've studied in international schools my whole life, so this is easy. I don't know about other students.

Bashayer is someone who has been functioning in a multicultural academic environment for some time and has developed a sense of intercultural intelligence. The $3^{\text {rd }}$ cultural space which is as defined by Knowledgeworkx is something that has seemingly grown inside her over time and experience with negotiated educational models (Knowledgeworkx Inc., 2013). My contention is that this response as well as others in later data show that time can be a major contributor to the ability to achieve intercultural competence and eventually develop this into intercultural intelligence. Bashayer has spent 
years immersed in this multicultural learning environment and thus her comments reflect that she has experience less difficulty adapting to it.

It seems both faculty members and students alike who have spent more time in education together in the UAE have altered their expectations of each other to come to more shared understanding. As mentioned by Peterson, intercultural competence can be viewed as the bare minimum needed to function in an intercultural environment while intercultural intelligence is a heightened level in which the individual can actively engage interculturally and thrive in the environment (Peterson, 2004). Bashayer's response shows evidence of this. She further cites time and exposure to certain teaching styles in saying,

Bashayer, UAE: I can relate and understand all of my teachers. Most of my primary and secondary school teachers were British so I guess I get their way of teaching. They understand Emirati students too so they know where I'm coming from. Sometimes it's different from my Arab teachers but my home life is of course Emirati so because of that I think I can relate to them too. I had to know how strict they are to the $U$ of E rules, but once I got that, everything has been fine.

As Bashayer states, this level of comfort with a multicultural teaching faculty has come from years of experience learning with such diversity. She mentions, the "British teachers" and the collaboration that they employ. This has surely come from the years and experience they have had with Emirati students. From the data, we can see that teachers with a longer record of experience teaching and dealing with Emirati students seem to have done this as well whereas data from newer faculty members showed that there are still levels ranging from apprehension to discomfort to frustration in understanding and working with Emirati students. Hanna, with only 2 years' experience, vents,

Hanna, England: I've given up on trying to understand these guys. I have to accept their way of life because I live here but I'll never agree.

The negotiated $3^{\text {rd }}$ cultural space between multicultural teaching faculty and Emirati students is something that takes time and mutual understanding. Students like Bashayer and as we will see later, teaching faculty like Murphy have extensive experience with "the other" and the shared understanding of their expectations. In my experience and from the data collected from both students and faculty members with differing levels of experience with each other, it seems this time is critical in creating this space which results in a harmonious learning environment. When questioned about the multitude of challenges that Emirati students face in a learning environment with a multicultural teaching faculty, Bashayer responses show her levels of ease and lack of difficulty while Hanna, who has only been in the country for 2 years has already "given up" and gives a sense of frustration. The fact that she mentions that "I have to accept" certain aspects of Emirati culture because she lives here evidences the fact that the $3^{\text {rd }}$ cultural space which is necessary for intercultural intelligence may be an aspect of her teaching approach which has not yet been fully realized. In fact, according to Bennett's DMIS, she only seems to be at the $4^{\text {th }}$ stage of this which bleeds into definitions of intercultural competence though not completely (Bennett, 1993).

\subsection{Conclusion}

I am reminded of Goodenough (1982) who stated "A society's culture consists of whatever it is one has to know or believe in order to operate in a manner acceptable to its members" (p. 54). The unique situation in the $U$ of $E$, is that the faculty 'members' are not of the native culture in which they live and operate. In some ways, we all 'operate' according to Emirati culture (i.e. observance and respect for a religion that for many of us is foreign, Islam). However, as opposed to what is often the case in living in other parts of the world, certain forms of assimilation are not required here (i.e. speaking the language 
of Arabic). Therefore, it seems many expatriates living and working in the UAE, in this case the teachers, often 'operate' under guises of both local Emirati culture and their own native ontology. Thus, discrepancies of how we operate in terms of teaching and learning are likely to occur.

We can see from responses presented here that both faculty members and the students alike acknowledge the fact that the $\mathrm{U}$ of $\mathrm{E}$ is an educational environment which is considered multicultural. This has presented many perceived benefits for both the students and faculty. However, it also presents challenges in the eyes of the student terms of the intercultural competence required for them to function and thrive academically from class to class. Considering the numerous cultures that students are taught by on a daily basis, I see their levels of intercultural competence as a more difficult challenge. Referring back to Byram \& Zarate's (1997) definition of intercultural competence as having double points of view and the ability to adapt one's behavior's in relation to the duality of beliefs, it seems the students are having to do this multiple times a day. What students are forced to negotiate is a "set of cultural behaviors" which Peterson (2004) cites the ability to engage as having intercultural intelligence.

It also presents challenges amongst the faculty regarding the professional relationships and agreement on academic issues which can, at times be characterized as strained. It is clear that heightened levels of intercultural competence are crucial in successful academic and professional practices at the $U$ of $E$. While some participants seem to have a firm grasp of this, it is evident that this was through experiential learning about the working and teaching dynamic of the institution through which this has developed. Fresher faculty members have shown signs of more frustration. These participants seem to have yet to attain higher levels of intercultural competence.

Significance of the study exists in the very fact that with globalized, transiting, international and ever-widening circles of academia, multicultural teaching faculties will become and are becoming the norms rather than the exception in campuses all over the world. The issues discussed here are certainly not exclusive to the Dubai Campuses of the $U$ of E. Many aspects confined to the perceived dimensions of Emirati culture no doubt exist in all public institutions of higher learning in the United Arab Emirates and over-arching themes of intercultural competence can be seen on any campus which opens its doors to diversity.

\section{References}

Arksey, H., \& Knight, P. (1999). Interviewing for social scientists. London: Sage.

Bennett, M. (1993). Toward ethnoreltivism: A developmental model of intercultural sensitivity. International Journal of Developemnt in Higher Education, 51-60.

Brown-Glaude, W. (2009). Doing diversity in higher education: Faculty leaders share challenges and strategies. Piscotaway, NJ: Library of Congress Publications.

Chapman, D., Austin, A., Farah, S., Wilson, E., \& Ridge, N. (2014). Academic staff in the UAE: Unsettled journey. Higher Education Policy, 131-151.

Crotty, M. (1998). The foundations of social research: Meaning and perpsective in the research process. St. Leonards: Allen \& Unwin.

DeCapua, A., \& Wintergerst, A. C. (2004). Crossing cultures in the language classroom. Ann Arbor: University of Michigan Press.

Diallo, I. (2014). Emirati students encounter western teachers: Tensions and identity resistance. Learning and Teaching in Higher Education: Gulf Perspectives, 11(2), 1-14.

Foucault, M. (1980). Power/Knowledge: Selected interviews and other writings, 1972 - 1977. New York: Panthenon Books.

Hamdy, D. S. (1960). Temperment and character of the Arabs. New York: Twayne Publishers.

Hofstede, G. (1980). Culture's consequences. Beverly Hills: Sage.

Holliday, A. (2002). Small cultures. Applied Linguistics, 20(2), 237-264.

Holliday, A. (2005). The struggle to teach English as an international language. Oxford: Oxford University Press. 
Knowledgeworkx Inc. (2013). Cultural mapping \& navigation. Dubai, UAE: Wiley Publishing.

Marton, F. (1986). Phenomenology: A research approach to investigating different understandings of reality. Journal of Thought, 21(3), 28-49.

Moore-Jones, P. (2014). Teaching approaches and teachers' perceptions in varying cultures. Journal of ELT and Applied Lingusitcs, 2(2), 28-49.

Moustakas, C. (1994). Phenomenological research methods. Thousand Oaks, CA: Sage.

Mughan, T. (1998). Integration of foreign cultural awareness into business language teaching materials and methods. Language Learning Journal, 17(1), 41-48.

Muller, R. (2001). Honor \& Shame: Unlocking the door. New York: Xlibris Publications.

Peterson, B. (2004). Cultural intelligence: A guide to working with people from other cultures. Boston: Intercultural Press.

Said, E. (1993). Culture and imperialism. New York: Vintage Books.

Watts, M., \& Ebbut, D. (1987). More than the sum of the parts: research methods in group interviewing. British Educational Research Journal, 13(1), 25-34.

\section{Contact}

P. J. Moore-Jones

University of California, Irvine, Department of Humanities

420 University Drive, Irvine, CA 92669

moorepj@uci.edu 